\title{
Regulation of Social Times during the COVID-19 Period: A Replication and Extension of the Work Activity Regulation Model
}

\author{
Hanen Khanchel ${ }^{1}$ \\ ${ }^{1}$ Institute of Advanced Business Studies, University of Carthage, Tunisia \\ Correspondence: Hanen Khanchel, Institute of Advanced Business Studies, University of Carthage, Tunisia. E-mail: \\ Hanen.khanchel@gmail.com
}

Received: June 23, 2020

Accepted: August 25, 2020

Online Published: September 16, 2020

doi:10.5430/bmr.v9n3p14

URL: https://doi.org/10.5430/bmr.v9n3p14

\begin{abstract}
The present study replicates St-Vincent et al., in 2011 experience sampling study of the work activity regulation model and addresses health crisis issue, which replicates the original study's findings. Results suggest that social times is regulated within each Tunisian manager. Individuals' or collective optimal social regulation state changed from public and organizational policies, but results did not support the original study's claim regarding social satiation. Similarly, the study showed a significant number of events involved a risk to their occupational health and safety. However, the thematic analysis reveals disparities in the distribution of risk events for the manager as well as the type of risks to which he is exposed during the COVID-19 period. So, there are a significant number of managers who were confronted with a risk to their health more than times when unforeseen events occur. These events experienced by Tunisian managers during the COVID-19 period can be stressful. In fact, in order to withstand the stress inherent in each of the life spheres, some people want to maintain a permeable border between work and non-work to avoid overflows from one to the other.
\end{abstract}

Keywords: time, regulation, spheres of life, COVID-19, workplace, manager

\section{Introduction}

The social times articulation, by its complexity, has different facets and contradictions. This articulation gives rise to regulatory behaviors in the actors that make it possible to reduce these overlaps and overcome these interferences. These modes of regulation or adaptation may relate to public and organizational policies aimed at reducing the frictions resulting from interference between spheres of life. They can also relate to the initiatives taken by individuals, couples or families with a view to achieving the balance between professional and family demands. Analysis of all of our interviews indicates that regulation between spheres of life during the COVID-19 period can be accomplished through a combination of several factors. Such as the enrichment felt and a positive relationship to the profession, family and / or organizational support. The executives questioned thus state that they use various measures for a better articulation between work and non-work. These measures may be related to their professional or private life. This research also allowed us to put into perspective the relationships between the spheres of life and to question the pre-existing simplistic relationships. Thus, we were able to identify the different interactions that may exist between spheres of life, such as conflict, enrichment, overflow and their reciprocal consequences during the COVID-19 period. It thus emerges that each of the theories used in the literature does not make it possible to express, independently of the others, all the relationships that may exist between work and non-work. We have thus shown that the theory of role conflicts (Greenhaus \& Beutell, 1985), the theory of enrichment (Greenhaus \& Powell, 2006), the theory of borders (Campbell-Clark, 2000) and those of systems (Curie \& Hajjar, 1987) are not contradictory but can coexist and complement each other to better express the experiences and perceptions of managers of the different interactions between work and non-work.

The present study will examine the modes of articulation between spheres of life among Tunisian managers during the COVID-19 period. This model will be centered on the active person (proposed by Vézina in 2001 and adapted by St-Vincent et al. in 2011). Although many modes of regulation will be studied, they focus more on the following themes: Enrichment, spousal and family support, informal arrangements, flexible working hours, leave and career interruption. 


\section{Conceptual Framework}

The conceptual framework used in this research, as well as in the action research above, is centered on the active person (proposed by Vézina in 2001 and adapted by St-Vincent et al. in 2011).

In this model, the articulation between spheres of life is considered to be the result of a balance between the professional sphere and the personal sphere to cope with it, linked to insufficient time for regulation (Maxime et al., 2019).

According to this theory, the social activity of manager in a situation is influenced by individual and environmental factors, known as the determinants of the activity. In addition, the manager's work activity will have consequences on his state of health, safety and ability to meet production requirements during the COVID-19 period. Thus, the activity work, characterized by the implementation of different strategies, is a response to determinants of work and will result in the balance between spheres of life. According to this conceptual framework, the occurrence of an unforeseen event linked to the crisis health is considered according to the determinants of the work in question, the strategies deployed to cope (regulation of social times) and consequences for health and productivity resulting from it (see Figure 1)

Support and means provided
Social Interactions

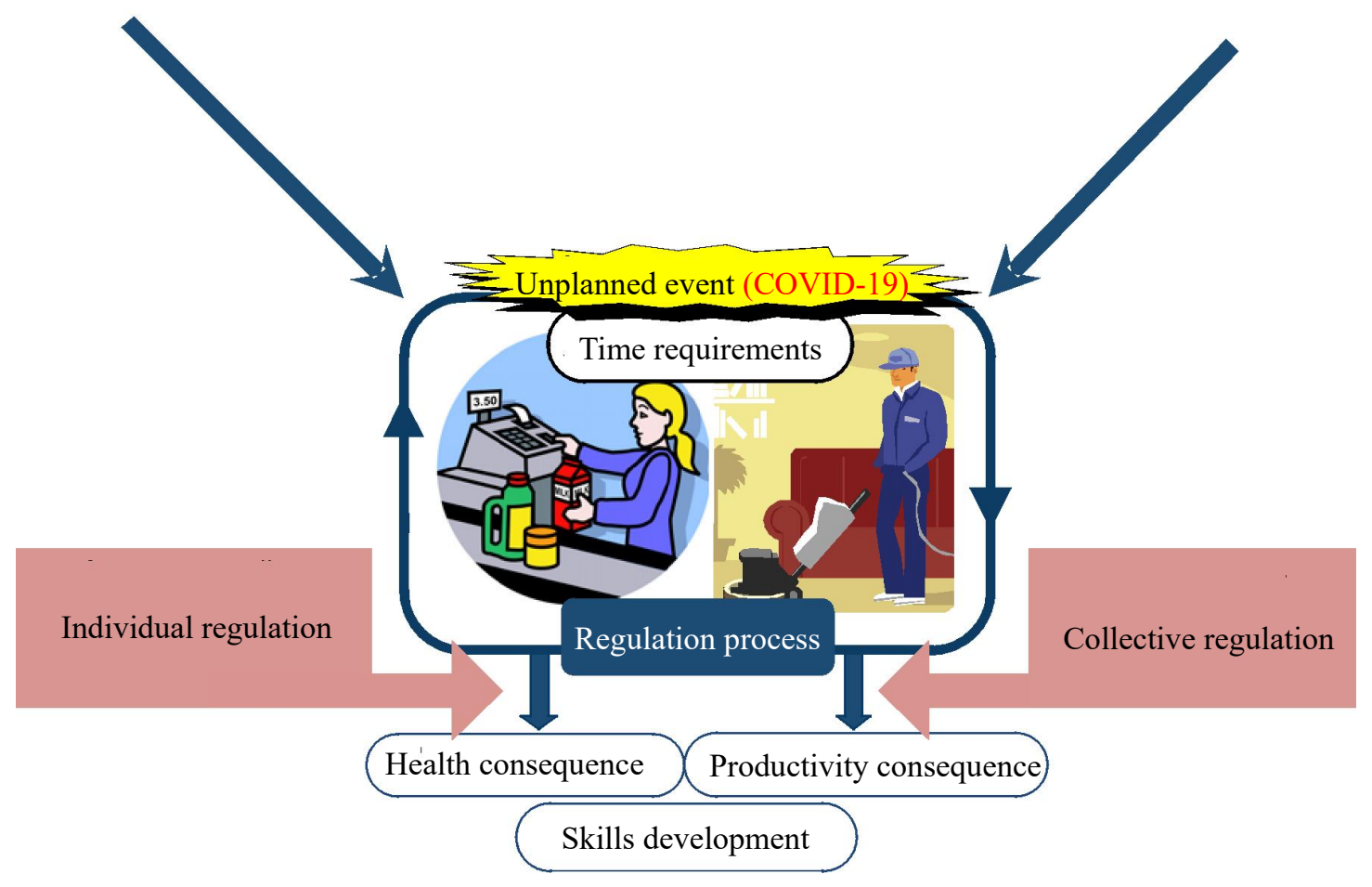

Figure 1. Regulation of social times model during the COVID-19 period

Inspired by the work activity regulation model (St-Vincent et al., 2011)

\section{Methodology}

The empirical research requires the selection of the organizations in which the data will be collected during the COVID-19 period. The composition of the sample influences the internal and external validity of the study (Royer \& Zalowski, 2003). This section presents the sample constitution process with regard to the research objectives. The choice of companies and respondents was made under at least three constraints: problematic, variety, and accessibility (Demers, 2003; Miles \& Huberman, 2003; Plé, 2006). We paid particular attention to the diversification of our sample by increasing the number of companies and sectors of activity studied. The desire to involve several organizations is 
justified by the necessary consideration of different organizational context and values. "The idea here is not to have statistical representativeness and a complete sample. The idea is to have sufficiently explored the variety of situations." (Romelaer, 2005, p. 106).

The sample of a qualitative study cannot be statistically representative of the population but must ensure at least a good diversity (Andréani \& Conchon, 2005). In order to take into account a diversity of individual characteristics and organizational behaviors, several executives per organization were interviewed. Large samples create practical difficulties, in terms of time and cost (Royer \& Zarlowski, 2003). It is then a question of finding a compromise between the temporal and material constraints and the constraints linked to the validity of the research. The heart of the problem is thus "to minimize the size of the sample under constraint of obtaining a satisfactory confidence of the results" (Lepers, 2003, p.178). Our wish is to succeed in constituting a sufficient sample to significantly demonstrate the phenomenon studied.

To constitute our sample, we used the "reasoned choice" method (Thietart et al., 2003, Evrard et al., 2000). This non-random method, also called empirical method (Evrard et al., 2000) seeks to constitute a sample from typical elements of the population. This method is essentially based on the judgment of the researcher, they are distinguished from probabilistic methods, where one seeks to eliminate his subjectivity (Royer \& Zarlowski, 2003). Unlike random methods, reasoned choice methods do not require any particular representative selection procedure or sampling frame (Royer \& Zarlowski, 2003). This sample selection method is consistent with the objective of our research which does not claim the representativeness of the sample in relation to the theoretical universe of reference.

Finally, we tried to compose a sample of 40 managers working in various sectors of activity. Likewise, for this sample to encompass a sufficiently large panel of professions, we systematically sought to interview production executives and support function executives. The selection of companies and executives was therefore essentially based on these two criteria.

Interviews were thus carried out with 40 managers belonging to 6 companies located in greater Tunis in 3 distinct activity sectors. Namely, the information and communication technologies sector, the service sector, and the banking sector. The choice of these three sectors of activity was not arbitrary, but it was motivated by the high level of supervision they experience (CRES, 2012).

\section{Results}

The following part presents the results from a thematic analysis of this qualitative study during the period of COVID-19. The findings are divided into three sections:

- The first section is devoted to the study of enrichment as a regulator of the articulation between spheres of life.

- The second section is devoted to the study of provisions relating to the sphere of non-work.

- The third section is devoted to the study of provisions relating to the sphere of work.

\subsection{Enrichment as a Regulator of the Articulation Between Spheres of Life}

Our interviews reveal that the enrichment felt by one of the spheres could play the role of regulator to protect individuals from the negative consequences of work-outside work interference during the period of COVID-19: it is a source of regulation between spheres of life. Indeed, ambition, development prospects, psychological and physical resources, and material resources obtained in one of its roles could be used and applied to improve performance in the other role, and vice versa. In addition, the resources provided by one of the roles could produce positive emotions in the other role, especially when this supporting role is central to the identity of the individual (Ashforth et al., 2000; Rothbard, 2001) .

"I have two children. They seem happy, I am fulfilled. . It's true that when I come home from work, I have another life that begins: taking care of the children, preparing dinner, doing homework, ..., but it gives me more energy, including for work, that she does not take me".

(Woman, 43, Operation \& developpement Manager, MIB)

The words of our interviewee underline the fact that a family bond can support the individual and create a useful energy to achieve performance in the professional sphere.

"I work with passion, when I accomplish a goal, when I come home at night I am so happy."

(Male, 44, Senior Consultant, FMT) 
This example illustrates the fact that a positive relationship to the profession and a strong professional commitment can play the role of an adjunct to the reconciliation between spheres of life. In other words, investment in the private sphere, especially in the family, is not necessarily synonymous with disengagement from the professional sphere, but can on the contrary be a source of enrichment (Alis \& Dumas, 2010, p.77) .

This enrichment felt by the fulfillment of a role is consistent with the words of Khanche and Kahla (2018) Ben Hassine (2007) and Elamdouni (2006) who evoke that the fulfillment and pride provided by work allow fulfillment and satisfaction not only professional but also personal. In this situation, engagement in non-work activities does not reduce involvement at work, but on the contrary promotes it (Alis \& Dumas, 2010, p.80). Likewise, recognition of the work accomplished can also modify the perception of individuals about their working time and their commitment to it. This recognition allows them to better tolerate the large volumes of work and the difficulties in reconciling the spheres of life. This brings us back to the theory of enrichment, which postulates that participation in certain roles generates resources (performance or affect) which can be used in other roles (Lourel \& St-Onge, 2012). In this case, gratification and satisfaction replace conflict and stress (Martin-Canizarès, 2009). Involvement in the role of work generates the reinforcement of self-esteem and new experiences and skills that promote performance at work since professional roles are better valued socially than family roles (Grzywacz \& Mark, 2000). Thus, a better balance between work and non-work is an important lever for improving quality of life and commitment to work (Alis \& Dumas, 2010, p.87) . This proven enrichment is an essential means for a better articulation between the professional sphere and the private sphere.

\subsection{Provisions Relating to the Sphere of Non-Work}

The interviews highlighted the extent to which the out-of-work situation could influence the perception of balance between work and out-of-work such as physical and psychological support from the spouse and also the support from other family members. In fact, the support of the spouse, or of another member of the family, in particular the parents, tends to reduce the burden of responsibilities outside work and can minimize the perceived role conflict during the COVID-19 period.

\subsubsection{Spouse Support and Role Sharing}

Research shows that spousal support is negatively correlated with work-off-work conflict for both women and men (Wiersma et al., 1991). It also allows and reduces the level of professional stress in men (Bures et al., 1996 cited by Challiol-Jeanblanc, 2006 ). For our respondents, the support of the spouse and the sharing of roles are considered to be one of the main sources of adjustment of the articulations between areas of life. According to Challiol-Jeanblanc (2006) support between spouses can be emotional (such as the demonstration of friendship, intimacy, attachment, listening, etc.) and / or instrumental (concrete actions, such as rendering service, giving information, giving advice, etc.). This is an essential element which contributes to reducing the difficulties in reconciling work and non-work. This is all the more relevant for dual career families. Indeed in this case, the two spouses are confronted with the scarcity of the time resource and consequently with a possible conflict between work and outside work.

Indeed, our respondents believe that the sharing of tasks and roles in the couple allows better living the articulations between areas of life and it is likely to reduce the perceived conflict between work and non-work.

"With my wife, we have a well-defined schedule, each with clear tasks in our daily life. This is what helps us to have a certain balance".

(Male, 44, Senior Consultant, FMT)

The sharing of responsibilities, domestic tasks and taking care of children represents a form of support between spouses. This is likely to make possible a more harmonious and balanced work-non-work relationship. An emotional support between spouses may prevent the emergence of conflicts between the professional sphere and the family sphere. In fact, this emotional support is likely to reduce perceived stress and conflict by allowing individuals to feel that their difficulties are understood, accepted and even shared by others, in particular the spouse.

\subsubsection{Support from Parents and In-Laws}

The family and in-laws are a source of support for salaried parents. They mainly intervene in childcare and domestic work, which frees up time for parents. Our interviewees, and in particular those with young children, believe that without the support of their parents and / or their parents-in-law, they would not have been able to "hold on".

"My mother and my mother-in-law help me a lot, both physically and psychologically".

(Female, 32, Head of Management Control Division, ANCE) 
It is mainly mothers and mothers-in-law who represent an irreplaceable support for working parents. They are called upon to look after the children or more occasionally when a child is ill and it is impossible to leave work. They can also be used to allow parents time for leisure or other entrepreneurial activities. Child care is the main form of support provided by mothers and mothers-in-law. Parents and parents-in-law can also intervene to look after the children during school holidays, a period when many employees consider it difficult since it is impossible to leave the children alone at home. Child care is therefore the task for which the support of parents and step-parents is most frequently requested. The executives interviewed calling on their parents to help them with activities in the family sphere, emphasized the importance of this support in the organization of their family life. This support clearly contributes to a better reconciliation between the professional sphere and the private sphere.

"Fortunately my mother helped me a lot ; without it, I think my children would be lost".

(Female, 34, Chief financial officer, MIB)

\subsubsection{Services as a Source of Support}

The burden of domestic and parental tasks makes the work-life balance even more difficult during the period of COVID-19, mainly for women on whom the main burden of these burdens rests. Calling on outside help, especially household help, is a coveted solution because it frees up "family time". It is one of the means used to limit the extent of family responsibilities and reduce the constraints linked to reconciliation between the private and professional spheres. We also note that executives use childcare services (such as crèche, kindergarten or other informal childcare services). For parents with preschool-aged children, calling on these childcare facilities is an essential means of being able to maintain their activity, especially for mothers.

\subsection{Provisions Relating to the Sphere of Work}

The provisions relating to the sphere of work are the adjustments and arrangements in the professional sphere which make it possible to take charge of the dimension of the sphere of non-work without disrupting professional life. They also relate to public and organizational policies aimed at reducing the friction resulting from interference between the professional and private spheres during the period of COVID-19.

\subsubsection{Individual Regulation: Informal Arrangements}

Our interviews revealed that the work-non-work relationship is not necessarily facilitated by identifiable and institutionalized organizational practices. In fact, flexible working hours and teleworking have not yet entered Tunisian companies. Face-to-face work is still the only accepted way of working. To remedy this institutional rigidity, managers are led to use informal scheduling practices, such as being absent for a few hours to resolve a problem or in the event of an emergency. But this remains subject to the will of the hierarchical superior. These informal arrangements are generally used as needed when the employee expresses an individual request to their immediate supervisor. They are treated individually on a "case by case" basis during the period of COVID-19.

"I have a work in progress, I have to leave my office several times a day, to supervise the progress of the work. This does not pose a problem as long as it does not block the service".

(Male, 37, accounting manager, ATB)

Late arrival is also a usual practice among Tunisian executives. This phenomenon generally increases for women with the arrival of the first child. For whom, it is a COVID-19 period that corresponds to learning the role of mother added to that the pressure of the family and professional sphere.

In talking to some of the interviewees, they said that they arrive late because of the dependent children they are required to accompany to school. This is combined with the remoteness of the home from the workplace and the traffic jams encountered during rush hour. The executives interviewed estimate that they lose in less 2 hours every day in transport. This is in addition to the fact that the companies in which we conducted our interviews are located in the greater Tunis which is characterized by the dispersion of activities and services with in addition a congestion of car traffic and a deficiency of the public transport system.

"All these trips are stressful and consume time and energy!".

(Male, 39, Head of the Personnel and Training Department, ANCE)

Late arrivals and absences remain a common practice among Tunisian executives. The installation of a biometric clocking system, and the monitoring by surveillance camera have not really affected the delays which continue to be tolerated as long as they remain within reason. But in private sector companies where the control system is more 
stringent than in public companies, employees tend to be absent less and if this happens, they have to justify themselves.

\subsubsection{Logistical Support From the Employer}

Several studies have shown that supervisor support can play a moderating role in work-off-work conflict (Ju et al., 2015). But Tunisian companies have not yet internalized, as is the case at the international level, the importance of employer support and more particularly the " pro-family measures "which aim to facilitate employees reconciliation between work and non-work. Tunisian leaders still have great difficulty in integrating the issue of the articulation between work and life outside of work into their priorities and have strong reservations about precautionary measures such as teleworking or the reorganization of working hours during the period of COVID-19.

We therefore did not find in the companies in which we carried out our survey any provisions facilitating work-non-work reconciliation (such as daycare, crèche, teleworking, etc.) with regard to what is happening in the United States or in Europe. With the exception of a bus set up by the company, in particular the ANCE and TT companies, to save their employees' time by dropping them off in the morning at their workplace and bringing them home at night. We also note that some companies (4 out of 6 of the companies in our sample) grant their head of structures company cars to facilitate their travel. These provisions are a potentially effective means of reducing the impact of working time on the employee by allowing him to reduce travel time during the period of COVID-19, which is likely to increase the degree of employee satisfaction.

\subsubsection{Collective Regulation: Towards Greater Scheduling Flexibility}

A new legal measure proclaimed in 2020 grants civil servants with special conditions (dependent children, disabled children) a time flexibility during the period of COVID-19. This new measure is likely to formalize an already common practice (that of arriving late to be able to drop off children at school). This new measure gives employees a greater margin of freedom, particularly at the start of the day in return for compensation at the end of the day. As evidenced by one of the executives interviewed:

I can't be at 8 am at the same time in front of my daughter's school and at the office!

(Male, 44, Senior Consultant, FMT)

Despite the fact that in Tunisia there are not really family-friendly measures taken by the government or companies to support work-non-work balance. The proclamation of this new law, despite the fact that it does not change much on a daily basis, shows that there is beginning to be a real awareness of the importance of the question of the link between work and non-work (Lakhoua \& Kahla, 2013).

\subsubsection{Part-Time Work}

Switching to a reduced working time during the period of COVID-19 could be a favorable solution for a better articulation between the spheres of life. As one of our respondents testifies:

"In my opinion, the problem essentially stems from the work schedule. The ideal is to work a single session until 3 p.m. In this way the reconciliation between family and work will be easier".

(Woman, 46 years old, division head of investments and subsidiaries, ATB)

But to our surprise, of the 23 women questioned, 9 of them meet the necessary criteria to benefit from part-time work with two-thirds of the salary (law of July 2006). But none of them used this device. This practice is considered to be penalizing for the professional career and in divergence with the expectations concerning career progression. The financial motive also appears to be a determining reason for the refusal of such a solution. But it should also be noted that the existence of alternative solutions, such as informal arrangements, may explain the brake on the choice of the part-time work formula.

\subsubsection{The Holidays}

Taking rest leave, sick leave, or exceptional leave remains a solution used by executives who wish to deal with the demands of private life. Some executives say that they have to take time off during their children's exam period so that they can help them revise well. Others do it when one of their children is sick as evidenced by this excerpt:

"I have to stay with my son because he has health concerns, I have to apply for exceptional leave to take care of my son, I am the only one who can do it, I cannot do trust another person to take care of him".

(Female, 33, senior engineer, ANCE) 


\subsubsection{Career Break}

The career break causes a loss for the company with the departure of its knowledge capital. In addition, this departure can have a negative impact on the employees who remain since they will find themselves with an overload of work causing more difficulties to balance between work and non-work.

Interviews revealed that women often tend to refuse professional responsibilities because of their family obligations. They may also have to interrupt their professional career especially when their children are young, as evidenced by these various testimonies:

"I am exhausted, my family moved to Kef because of my husband's new job, I stayed here for work. This situation is becoming difficult. I am obliged to take unpaid leave while waiting to be transferred to Kef with my family".

(Woman, 34, Telecommunications Engineer, TT)

"My husband got an employment contract in Dubai. To join him, I am going to ask for a layoff for the reunification of spouses".

(Female, 32, Head of Management Control Division, ANCE)

As these testimonies show, women, especially if they have young children, tend to downgrade their professional commitment. They feel an immediate legitimacy to interrupt their careers to devote their time to their families or to join their husbands, even if this can have repercussions on their professional careers. This brings us back to the notion of the role attributed to each sex and the differences in the processes of socialization in our society (Lee \& Brotherdige, 2006). Women are educated from an early age as "protectors of the home". They are then more likely to view work as affecting the family (Thompson \& Walker, 1989) and are ready to sacrifice their professional careers to devote their time to their families.

Taking into account these remarks, observations and conclusions, we can say that the articulation between working time and time outside of work, by its complexity, has several facets and contradictions. This articulation gives rise to "positive" and "negative" regulatory behaviors in the actors, making it possible to reduce these overlaps and overcome these interferences. Several elements play a decisive role in facilitating the articulation between the professional sphere and the private sphere: such as the enrichment felt by one sphere of life and its positive repercussions on the other sphere, the support of the spouse and the family of 'on one side and the provisions offered by the professional sphere on the other. But these measures remain limited and are implemented mainly by the employees themselves. These different practices work together to achieve the desired adjustment between the different temporalities and make it possible to better manage the overlaps between the professional and private worlds.

\section{Discussion}

The Word cloud of events experienced by Tunisian managers during the COVID-19 period showed in Figure 2 more than 20 events involved a risk to their occupational health and safety (Khanche \& Kahla, 2019). However, the thematic analysis reveals disparities in the distribution of risk events for the manager as well as the type of risks to which he is exposed in public or private sector. So, there are three managers who were confronted with a risk to their health more than 15 times when unforeseen events occur in private sector than those in public sector. These events experienced by managers during the COVID-19 period can be stressful (Khanchel, 2019). In fact, in order to withstand the stress inherent in each of the life spheres, some people want to maintain a permeable border between work and non-work to avoid overflows from one to the other (Chrétien, 2005, p.28).

Many Tunisian managers weren't happy with the way their job was running their life during the COVID-19 period, so they quit, explaining in a blog post that immediately went viral how "We decided the only way to balance was by stepping back from our work."

While cutting back on work hours can be extreme during the COVID-19 period, there is an almost limitless amount of provision on how to achieve work-life balance. Try to keep up with the normal pace of activity, and at best we even prepare ourselves for burn-out and feeling ineffective when we can't achieve the impossible; at worst, we could "balance" ourselves out of a job.

So, rather than asking managers to give another list of provisions to achieve work-life balance during the COVID-19 period, we asked them which managers should really ignore if they want to preserve their mental health and their career.

"Negotiate a flexible schedule." These provisions come in many forms - so-called CEOs urge overworked managers to negotiate flexible hours, telecommuting privileges, job sharing agreements during the COVID-19 period and they tend 
to ignore a number of financial and cultural details (Khanchel, 2020). Furthermore, it seems that the context of health crisis experienced in Tunisia represents a factor pushing Tunisian managers to reduce, or even eliminate, face-to-face contact, isolation, wearing a mask... by health precautionary measures. The purpose of this government provisions is to set the methods and prescriptions for targeted containment, in accordance with the requirements of preventing the spread of the Coronavirus "Covid-19" and with a view to mitigating its repercussions on the health, economic, security and social.

The conditions, procedures and pace of resumption of activity of services, local authorities, public administrative establishments, public bodies, companies and establishments, are set by decision of the government responsible for the civil service, governance and the fight against corruption, which will be published on the electronic site of the Presidency of the Government. The conditions and procedures for resuming activity in the liberal professions regulated by specific texts are set by decision of the representative professional bodies, after coordination with the minister responsible for the sector, which will be published on the electronic site of the professional body and of the interested ministry. The private sector companies and self-employed workers interested in resuming activity may move out of their place of residence upon declaration with approval.

The model of the declaration as well as the procedures and conditions of its presentation or deposit, are fixed by decision of the Minister responsible for the sector which will be published on the electronic site of the Ministry concerned. The employer in the public and private sectors is required to make available to personnel, protection and safety devices in the workplace, in accordance with a manual of procedures for carrying out the activity, in accordance with health measures for the prevention of the spread of the coronavirus "Covid-19".

"Many managers in volatile private sector jobs during the COVID-19 period have negative-pressure situations and they cannot just come and go as they please", "Many workers, including managers who have jobs part-time, are scheduled just a few days in advance ... the selt-quarantine aspect alone makes life very complicated and difficult during the COVID-19 period.

Even if managers have the opportunity, flexible hours often mean sacrificing salaries, career opportunities, or both. "In the Tunisian workplace, there is a stigma of flexibility" (Lakhoua \& Kahla, 2013). Almost half of managers say they would take a pay cut to be able to work from home - so if the manager wants to negotiate for more working time in their career, be prepared for this context. And while the manager's finances are not an issue, getting permission to cut back on work may not be agreed upon with the CEO. According to the CEO, there are fewer managers allowing workers to go from full-time to part-time status and come back today than at the start of the health crisis.

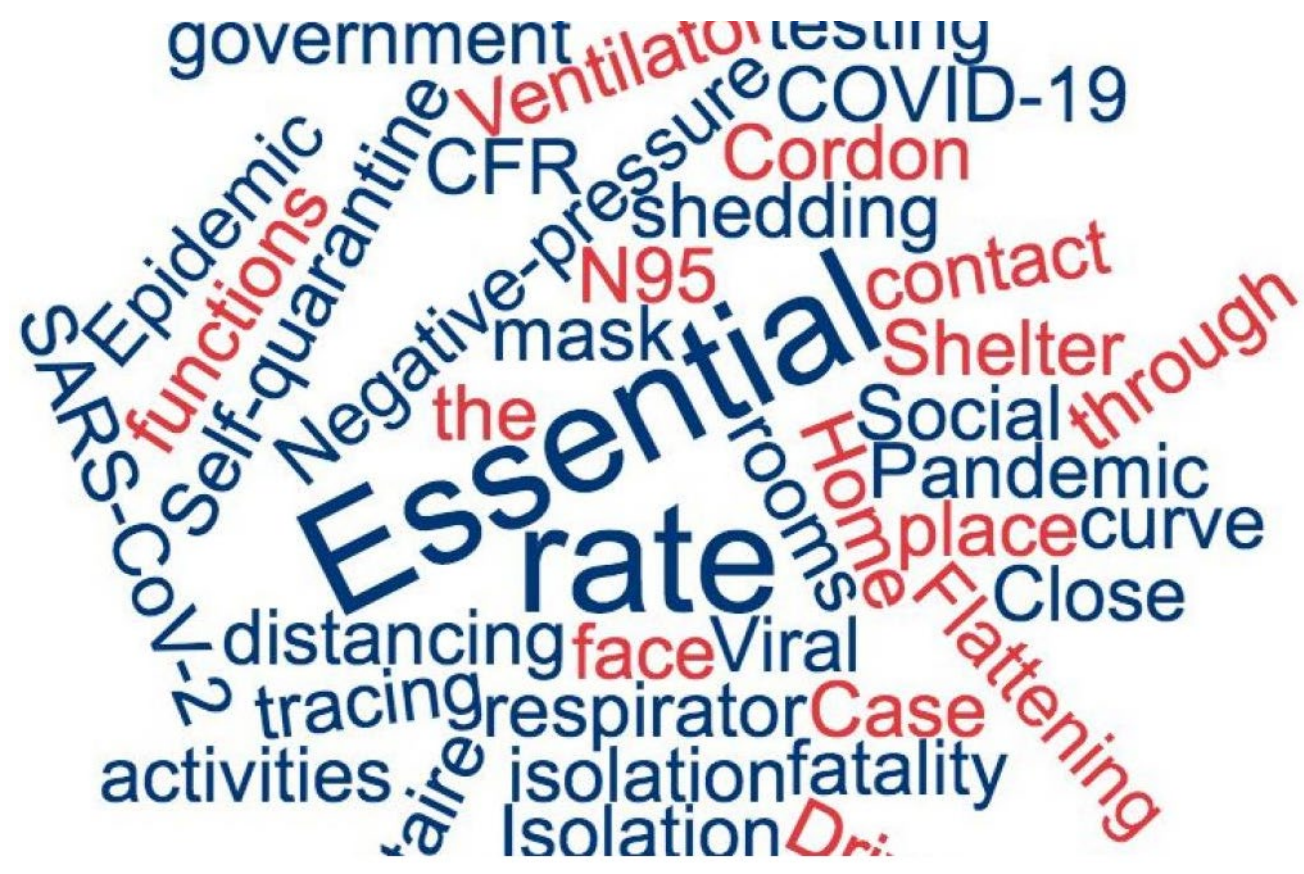

Figure 2. Word cloud of events experienced by Tunisian managers during the COVID-19 period 


\section{Conclusion}

This paper was the opportunity to present our findings obtained during the COVID-19 period thanks to the thematic content analysis concerning the determinants of the interference between working time and time outside of work and the modes of regulation between spheres of life. The first section allowed us to highlight the different determinants of the articulation between social times in the health crisis. As for the second section, it allowed us to highlight the different modes of regulation adopted by executives or offered by the organization to better regulate between the professional sphere and the private sphere during the COVID-19 period.

The thematic analysis allowed us to reveal a significant number of determinants of the articulation between working time and time outside of work. These factors have an effect on the practices and frequencies of the different types of articulation between areas of life. These determinants are thus articulated around four groups of variables:

- Personal characteristics: age did not seem to us to be a determining factor, but on the other hand, we noticed that men and women experience the relationship between working time and time outside of work differently: Men and women do not describe their implications in work in the same terms and do not express their expectations in terms of work-non-work articulation in the same way: men expect their wives to be understanding and support them in their professional commitments while women tend to reduce their professional commitment to better reconcile their work and their family even if it means sacrificing their careers.

- Relationship between work and non-work: Investment in work and non-work vary from one person to another. A positive relationship to work is likely to provide a certain satisfaction that replaces conflict or guilt. On the other hand, a negative relationship to work develops a feeling of guilt in the face of the difficulty of managing multiple temporalities.

- The characteristics of the position held also influence the relationship between work and non-work and the modes of adjustment between spheres of life. such as the number of working hours, the frequency of trips, the responsibilities granted.

- The norms and behaviors of the group at work can be more or less favorable to the development of practices which support or not the articulation between the social times such as the attitude of the hierarchical superior and the colleagues, the working conditions, the difficulty of delegate, etc.

We have also observed that the abusive use of ICTs during the COVID-19 period leads to an invasion of work on the non-work basis and blurs the line between private and professional life. These ICTs modify the temporal structures and the practices of Tunisian managers, in particular in terms of the overflow of working time onto other times of life. It is also interesting to note that our interviewees spontaneously refer the notion of balance or reconciliation between social time to the work-family interface, by concealing any other personal temporal experience, in particular leisure or associative life.

Future directions for the study of social times regulation are discussed during the COVID-19 period.

The main limitation of the study is the difficulty in generalizing the findings, considering the use of the St-Vincent et al., in 2011 experience sampling study of the work activity regulation model, which, because it represents a small number of Tunisian managers, may not reproduce common sense in such context of helth crisis.

\section{References}

Alis, D., \& Dumas, M. (2003). 35 hours, perceived organizational support and harmonization of family life/professional life. Revue de Gestion des Ressources Humaines, 50, 37-55.

Andreani, J. C., \& Conchon, F. (2005). Reliability and validity of qualitative surveys. A state of the art in marketing. Revue Française du Marketing, 201(1-5), 5-21.

Ashforth, B. E., Kreiner, G. E., \& Fugate, M. (2000). All in a day's work: Boundaries and micro role transitions. Academy of Management Review, 25, 472-491. https://doi.org/10.5465/amr.2000.3363315

Ben Hassine, A. (2007). Pathways of women executives in the Tunisian public administration: women (not) like the others. Télescope, 13(4), 42-53.

Burke, R. J., \& Greenglass, E. R. (1987). Work and family. In Cooper, C. L., \& Robertson, I. T., International Review of Industrial and Organizational Psychology (pp. 273-320). John Wiley \& Sons Ltd.

Burleson, B. R. (2003). The experience and effects of emotional support: What the study of Cultural and gender differences can tell us about close relationships, emotion, and interpersonal communication. Personal Relationships, 10, 1-23. https://doi.org/10.1111/1475-6811.00033 
Campbell, D. T., \& Stanley, J. C. (1966). Experimental and quasi-experimental designs for research. Boston: Houghton Mifflin Company.

Center for Research and Social Studies. (2012). Survey on the structure of wages, Tunisia 2011. Collaboration with the International Labor Office.

Challiol-Jeanblanc, H. (2006). Family and Career in Dual Career Couples. In El Akremi et al., (2006). Organizational Behavior: Organizational Justice, Career Issues and Burnout (pp. 168-188). De Boeck Supérieur.

Chrétien, L. (2005). La conciliation travail-famille dans les MRC de Bellechasse, Lévis et Lotbinière. Rapport de recherche. Québec: CRAD, INRS-Urbanisation et CAMF.

Curie J., \& Hajjar, V. (1987). Vie de travail, vie hors travail. La vie en temps partagé. In Lévy-Leboyer, C., Spérandio, J.C. (Eds.), Traité de psychologie du travail (pp.37-55). PUF, Paris.

Curie, J. (2000). Travail, personnalisation et changements sociaux. Archives pour les histoires de la psychologie du travail. Toulouse: Editions Octarès.

Curie, J., Hajjar, V., Marquié, H., \& Roques, M. (1990). Proposition méthodologique pour la description du système des activités. Le Travail Humain, 53(2), 103-118.

Demers, C. (2003). The interview. In Giordano, Y., Conducting a research project, A qualitative perspective (pp. 173-209). Paris, Éditions Management et Société.

Elamdouni, S. (2006). Women executives in Tunisia, portraits of a negotiation: from yesterday to today, between career and private life. Labor market and gender conference in the Maghreb countries, which labor markets? , March 15-16, 2006.

Evrard ,Y., Pras, B., \& Roux, E. (1997). Market: studies and research in Marketing (2nd ed.). Nathan.

Greenhaus, J. H., \& Kopelman, R. E. (1981). Conflict Between Work and Nonwork Roles: Implications for the Career Planning Process. Human Resource Planning, 4, 1-10.

Greenhaus, J. H., \& Powell, G. N. (2006). When work and Family are allies: A theory of work-family enrichment. Academy of Management Review, 31(1), 72-92. https://doi.org/10.5465/amr.2006.19379625

Greenhaus, J. H. (1988). The intersection of work and family roles: Individual, interpersonal, and organizational issues. Journal of Social Behavior and Personality, 3, 23-44.

Greenhaus, J. H., \& Beutell, N. (1985). Sources of conflict between work and family roles. Academy of Management Review, 10, 76-88. https://doi.org/10.5465/amr.1985.4277352

Greenhaus, J., \& Singh, R. (2003). Work-Family Linkages, A Sloan Work and Family Encyclopedia Entry. Chestnut Hill, MA: Boston College.

Grzywacz, J. C., \& Bass, B. L. (2003). Work, family, and mental health: Testing different models of work-family fit. Journal of Marriage and Family, 65, 248-262. https://doi.org/10.1111/j.1741-3737.2003.00248.x

Grzywacz, J. G., \& Butler, A. B. (2005). The impact of job characteristics on work-to-family facilitation: Testing a theory and distinguishing a construct. Journal of Occupational Health Psychology, 10, 97-109. https://doi.org/10.1037/1076-8998.10.2.97

Grzywacz, J. C., \& Marks, N. F. (2000). Reconceptualizing the work-family interface: An ecological perspective on the correlates of positive and negative spillover between work and family. Journal of Occupational Health Psychology, 5, 111-126. https://doi.org/10.1037/1076-8998.5.1.111

Imprimerie officielle de la république Tunisienne. (2020). Code de travail tunisien.

Ju, L., Jing, X., Lin, Z., \& Meng, D. (2015). The influence of abusive supervision on work-to family conflict: the mediation role of organizational justice. 2nd International Conference on Education Reform and Modern Management (ERMM 2015). https://doi.org/10.2991/ermm-15.2015.75

Khanche, H., \& Kahla, K.B. (2019). Representation of the Articulation between Spheres of Life. Business and Management Research, 8, 10. https://doi.org/10.5430/bmr.v8n2p10

Khanchel, H. (2019). Stress in the Workplace: Causes, Effects \& How to Cope. Journal of Business Administration Research, 8, 52. https://doi.org/10.5430/jbar.v8n1p52 
Khanche, H., \& Kahla, K. B. (2018). Gender-Role Stereotypes: Perception of Tunisian Leaders. Business and Management Research, 8, 10. https://doi.org/10.5430/bmr.v7n4p22

Khanchel, H. (2020). "Intertwining Practices and Uses of ICT: A Cultural Digital Analysis," Journal of Business Administration Research, 9(1), 21-32. https://doi.org/10.5430/jbar.v9n1p21

Lakhoua, H. K., \& Kahla, K. B. (2013). Impact of the Work Flexibility on Organization. International Journal of Innovative Research and Development, 5(4).

Lee, H., \& Liebenau, J. (2002). A new time discipline: managing virtual work environments. In R. Whipp, B. Adam, and I. Sab elis, Making Time, Oxford, Oxford University Press.

Lee, R. T., \& Brotheridge, C. M. (2006). Enrichment and reconciliation of the link between work and family. In El Akremi et al., Organizational behavior: Organizational justice, career issues and burnout, (pp. 189-205). De Boeck Superior.

Lepers, X. (2003). Exchange relations between large-scale distribution and its suppliers: the case of the Auchan brand (Doctoral thesis, Université Par is IX-Dauphine, Paris).

Lourel, M., \& Mabire C. (2008). The effort-reward imbalance and the spillovers between work and private life among dairy farmers: their effects on burnout. Public Health, 20, 89-98.

Lourel, M., \& St-Onge, S. (2012). From conflict to work-family enrichment: research results and perspectives. Work and Organizational Psychology, 18(2), 100- 101. https://doi.org/10.1016/S1420-2530(16)30087-5

Maxime, N., Mohsen, Z., René, B., Fabien, C., \& Yves, R. (2019). Intérêt de la Marge de Manœuvre Situationnelle pour le ciblage des situations à risque de Troubles Musculo Squelettiques. Activités [En ligne], 16-2, mis en ligne le 15 octobre 2019. https://doi.org/10.4000/activites.4588

Martin, A. C., Mègemont, J. L., Roquefort, A., \& Le Blanc, A. (2012). Nature and meanings of exchanges between areas of life: the example of the new frameworks of Social Action. Psychology of Work and Organizations, 18(2), 122-141. https://doi.org/10.1016/S1420-2530(16)30089-9

Martin-Canizarès, C., Mègemont, J.-L., \& Dupuy, R. (2009). Systemic and inter-individual approach to work / non-work relations: role of recognition processes in a situation of professional retraining. Psychological practices, 15, 255-270. https://doi.org/10.1016/j.prps.2008.09.007

Miles, M. B., \& Huberman, A. M. (2003). Analysis of qualitative data (2nd ed.). Brussels, De Boeck.

Plé, L. (2006). The coordination of a multichannel distribution network: the case of retail banking (Doctoral thesis in Management Sciences, Paris Dauphine University).

Rothbard, N. P. (2001). Enriching or depleting? The dynamics of engagement in work and family roles. Administrative Science Quaterly, 46, 655-684. https://doi.org/10.2307/3094827

Royer, I., \& Zarlowski, P. (2003). Sample (s). In Thietart R.-A. et al., Management research methods (p. 188-223). Paris: DUNOD.

Royer I., \& Zarlowski P. (2003). The design of research. In Thietart R.-A. et al., Management research methods (p. 139-168). Paris: DUNOD.

St-Vincent, M., Vézina, N., Bellemare, M., Denis, D., Ledoux, É., \& Imbeau, D. (2014). Ergonomic Intervention. Ed multiMonde: IRSST.

Thompson, E. P. (1979). Time, work and industrial capitalism. Revue Libre (1st ed., vol. 5, pp. 3-51, 1967 in Past and Present , n 38). https://doi.org/10.1093/past/38.1.56

Thompson, L., \& Walker, A. J. (1989). Gender in families: Women and men in marriage, work, and parenthood. Journal of Marriage and the Family, 51, 845-871. https://doi.org/10.2307/353201

\section{Copyrights}

Copyright for this article is retained by the author(s). with first publication rights granted to the journal.

This is an open-access article distributed under the terms and conditions of the Creative Commons Attribution license (http://creativecommons.org/licenses/by/4.0/). 